\title{
L'HOMME L'Homme
}

Revue française d'anthropologie

153 | janvier-mars 2000

Observer Nommer Classer

Jackie Assayag, L'Inde fabuleuse. Le charme discret de l'exotisme français (XVII $-\mathrm{XX}^{e}$ siècle)

Paris, Éditions Kimé, 1999, 249 p., bibl., films cités, opéras cités, ill., ph., cartes (« Le sens de l'histoire»)

Régis Meyran

\section{OpenEdition}

Édition électronique

URL : http://journals.openedition.org//homme/2626

DOI : 10.4000/lhomme.2626

ISSN : 1953-8103

Éditeur

Éditions de l'EHESS

\section{Édition imprimée}

Date de publication : 1 janvier 2000

Pagination : 310-313

ISBN : 2-7132-1316-9

ISSN : 0439-4216

Référence électronique

Régis Meyran, « Jackie Assayag, L'Inde fabuleuse. Le charme discret de l'exotisme français ( $x v{ }^{e}{ }^{e}-x x^{e}$ siècle) », L'Homme [En ligne], 153 | janvier-mars 2000, mis en ligne le 24 novembre 2006, consulté le 23 septembre 2020. URL : http://journals.openedition.org//homme/2626 ; DOI : https://doi.org/10.4000/ Ihomme.2626

Ce document a été généré automatiquement le 23 septembre 2020.

(c) École des hautes études en sciences sociales 


\section{Jackie Assayag, L'Inde fabuleuse. Le charme discret de l'exotisme français (XVII ${ }^{e}-\mathrm{XX}^{e}$ siècle)}

Paris, Éditions Kimé, 1999, 249 p., bibl., films cités, opéras cités, ill., ph., cartes (« Le sens de l'histoire »)

\section{Régis Meyran}

1 Ce livre s'attaque à une des catégories de l'imaginaire collectif les plus prisées par les ethnologues des sociétés « contemporaines » : l'exotisme. Si ce « régime narratif issu de la rencontre entre cultures et/ou civilisations" a servi sur le long terme à " appréhender l'altérité », il a surtout été un "processus d'exclusion» (p. 21). C'est ce processus que Jackie Assayag cherche ici à décrire, s'attachant plus particulièrement aux représentations tant savantes que populaires qui furent (et sont encore) celles des Français à propos de l'Inde. On sait que l'aventure coloniale française dans la péninsule fut de courte durée, puisque, commencée en 1666 avec la création du premier comptoir, elle s'acheva en 1761, date à laquelle ne subsistera plus que le minuscule Pondichéry qui deviendra indien en 1954. Malgré - ou à cause - de cette non-présence, l'Inde n'a jamais cessé d'inspirer les Français. C'est donc, à travers les productions littéraires et artistiques les plus diverses, à une rencontre avec des personnages parfois célébrissimes, parfois oubliés, que nous convie l'indianiste, le but assigné étant de débusquer « d'indéracinables préjugés » (p. 13).

2 Aux XVII ${ }^{e}$ et XVIII siècles, l'Inde est fortement représentée dans l'opéra. Chez Voltaire (dont les œuvres indiennes furent toujours censurées), comme chez Joseph Gaveau ou Martin Antoine Lemierre, c'est presque invariablement la même situation qui est mise en scène : un homme occidental (colon ou aventurier) tombe amoureux d'une danseuse indigène (la fameuse "bayadère »), mais leur amour est impossible; la belle se suicide en se jetant dans un brasier et le héros rentre chez lui. Il faut y lire, nous dit Jackie Assayag, une allégorie de la lutte, issue de la philosophie des Lumières, entre la « virile Raison occidentale » et la "féminine fantaisie orientale » (p. 44). Outre le personnage de la bayadère, tantôt danseuse lascive et dévoyée, icône de la « fascination érotique et 
[du] trouble exotique de l'orient » (p. 42), tantôt veuve moralement exemplaire qui se sacrifie pour son mari, le second rôle récurrent est très souvent dévolu au "prêtre fanatique ", ou "Grand Vizir ", incarnation du despotisme oriental. Si les caractères sont toujours exagérés, l'histoire et le lieu de l'action sont également irréels : l'Orient qui est donné à voir est "mythique ", "plus européo-indien qu'indo-européen » (p. 50). Finalement, à travers les opéras «indiens" s'édifie un «dictionnaire d'idées reçues, un musée de tics et une partition de stéréotypes» (p. 62). Les écrivains, de leur côtés, semblaient ne pas s'en soucier, l'œuvre n'étant qu'un moyen commode pour faire passer des revendications politiques ou morales (l'opposition à la traite des Noirs ou à la religion, la célébration du libre arbitre) en évitant la censure.

Jackie Assayag s'intéresse ensuite (chap. II) aux pièces de théâtre du XVIII siècle et montre que les mêmes buts politiques sont poursuivis : Les Brahmes (1783), de JeanFrançois de La Harpe, littérateur disciple de Voltaire, où sont évoquées les pratiques religieuses et les rencontres entre Indiens et musulmans, a en réalité pour objet la critique du christianisme et des régimes despotiques indo-mahométanes. Si les brahmanes sont relativement épargnés, voire idéalisés (ils attestent, par leur présence en tant que détenteurs des tout premiers textes sacrés, que l'Inde est le berceau de la Civilisation), on trouve une "vue dépréciative de l'hindouisme et caricaturale des mahométans » (p. 97). En bref, le théâtre « indien » des Lumières informe plus sur les mœurs occidentales qu'orientales, puisqu'il fait «de la scène un instrument d'éducation du citoyen et un lieu où se joue la tragédie nationale » (p. 98).

4 Les auteurs $d u \mathrm{XIX}^{\mathrm{e}}$ siècle reprendront grosso modo les même thèmes, mais en les accommodant d'une logique colonialiste (chap. III). Ainsi la pièce de Joseph Étienne de Jouy, Tippo-Saëb (1812), outre la nécessaire critique du despotisme oriental "gouvernement barbare, dépourvu de loi et réglé sur le seul caprice » d'un tyran dont «la férocité et la sensualité ne peuvent être qu'extrêmes »(p.118) -, est empreinte de «nationalisme anglophobe» (p.117) qu'on peut, entre autres, attribuer à la défaite française aux Indes. La morale inhérente à l'œuvre est que, au nom de la Raison et des valeurs universelles d'égalité, seule une forme de "paternalisme colonial français » est - bien mieux que la perfide Albion - susceptible de calmer les «imprévisibilités » du despote.

5 Dans le chapitre IV, Jackie Assayag relate le «désenchantement» qui affecta l'imaginaire oriental français à la fin du xIx siècle ; la transition est sensible quand on compare la célébration onirique de l'Inde par Théophile Gautier à la tristesse confinant au dégoût de Pierre Loti. Le premier, qui visite en 1838 des bayadères dans une villa parisienne, tombe sous le charme d'une « divine beauté », une "forme pure » chez qui «tout semble inconnu et, par conséquent, inestimable» (p.131), une «féminité essentielle ", "vestige d'une Origine oubliée » (p. 132). Quant au second, que son goût pour le dépaysement et le travestissement inclinait à être « soi-même une partie [du] tableau », il ne trouve en 1882 que des symptômes d'un "Orient désorienté » : ainsi sa bayadère est-elle une "créature d'artifice " qui se "pavane dans l'inauthentique " (p. 138), un être déguisé et androgyne qui le renvoie non seulement à son ambivalence sexuelle refoulée, mais aussi au "non-avenir d'un Orient que l'Occident a sans cesse dégradé » (ibid.). Ce désenchantement, note Jackie Assayag, est contemporain du développement des théories eugénistes et sociales-darwinistes: écrivains et scientifiques expriment la vision d'un Orient soudain devenu impur, ainsi que la peur d'une invasion asiatique et de la décadence de l'Occident. 
6 Les thèmes de prédilection d'Arthur de Gobineau (la dégénérescence de la race et le déclin de la civilisation) et de Georges Vacher de Lapouge (le racisme bioanthropologique), seront repris à satiété au moment de l'Occupation allemande. L'idéologie nazie imprégnera non seulement les milieux scientifiques « collaborateurs », mais bon nombre de productions culturelles françaises ${ }^{1}$ L'exemple paroxystique en est la bande dessinée L'Inde fabuleuse (1944), publiée par l'illustré français Le Téméraire, à laquelle Jackie Assayag consacre le chapitre V. Cette histoire raconte l'épopée d'une tribu d'« Aryens » (les seuls descendants des Atlantes à n'avoir pas dégénéré parce qu'ils avaient été isolés pendant des millénaires en Europe $\mathrm{du}$ Nord) qui part à la conquête de l'Inde. Le protagoniste principal et chef du groupe, Sigur - double de Siegfried -, est le prototype de l'homme grand, blond aux yeux bleus, dolichocéphale et leptoprosope, qui arbore fièrement la svastika autour du cou. Tout, dans la bande dessinée, annonce " la morale d'un Ordre nouveau, fondée sur les valeurs de la maîtrise virile et de la domination légitime » (p.155). Leur installation en Inde se fera non sans peine, car les vaillants guerriers auront à combattre "d'étranges petits hommes noirs ». Après qu'ils aient été mis en fuite, les dernières paroles de Sigur, mourant, seront: "Vous devez chasser les hommes noirs. Ne vous alliez jamais avec eux, ce serait votre perte» (p.156). On ne pouvait résumer plus clairement la haine nazie pour les "hordes asiatiques" et la volonté de préserver la race nordique. Malheureusement pour eux, les Indo-Aryens vont oublier peu-à-peu la «loi de la race »: "ils se sont mélangé aux indigènes, s'affaiblissant de la sorte» (p. 158). Désormais, les princes, « uniquement occupés de leurs plaisirs qu'ils satisfaisaient dans les cours fastueuses " (ibid.), dégénèrent.

7 Les historiettes du Téméraire, conclut Jackie Assayag, sont le reflet des préoccupations des scientifiques français acoquinés avec l'intellingentsia allemande. On sait quelle fut l'obsession de la pureté de l'ethnie et du sang chez l'« ethnologue » George Montandon et l'«anthropologue " René Martial, tous deux furieusement antisémites, dont les parcours sont brièvement évoqués. Martial aurait par ailleurs signé sous un pseudonyme un article de «vulgarisation» raciste («Les secrets du sang »), dans le Téméraire, preuve de son souci d'endoctriner les jeunes Français (pp. 161-166).

8 Mais que resta-t-il après la guerre de cette hantise du métissage ? Le dernier chapitre confirme qu'elle est loin d'avoir disparu avec les fascismes. L'exemple du cinéma français des années 50 est à ce sujet révélateur, que l'on considère les œuvres de réalisateurs de renom, comme Jean Renoir, ou de moindre notoriété : il a multiplié les stéréotypes s'agissant de l'Inde. Le colon français y est souvent vu comme un raté, l'indigène comme un être primitif, le métis comme amoral et dégénéré. Preuve s'il en est que le «paternalisme impérialiste » et le darwinisme social de Gustave Le Bon (qui avait la «phobie des contacts interethniques»; p. 200) ou de Clémence Royer (la traductrice française - et détractrice - de Darwin) restent au goût du jour. Le métis, « créature de l'exotisme tardif» (p. 203), viole le principe d'identité puisqu'il est un « acatégorisé » (ibid.) : nécessairement impur, il est rejeté de tous. Dans les années 60, il laissera la place à son double "de l'intérieur ", l'immigré, victime de la colonisation et de la décolonisation.

9 Au bout du compte, l'auteur nous livre un ouvrage éclectique et érudit, qui laisse toutefois le lecteur à des pensées amères tant le propos est pessimiste, voire désabusé : la rencontre entre Orient et Occident n'a jamais eu lieu... À sa place s'est constitué un 
exotisme au charme plus que « discret » (pour reprendre l'euphémisme du sous-titre), que Jackie Assayag qualifie de "mensonger et dangereux", quand il n'est pas carrément « abject » (p. 220), puisque l'Autre sera toujours un Sauvage à éduquer ou un sous-homme à éliminer. Dans tous les cas de figure, l'exotisme reste un «espace vide, dépourvu de mémoire et de relation, un non-lieu » (p. 221). L'Inde fabuleuse fait le procès édifiant d'un imaginaire occidental entaché de perversité. Un ouvrage passionnant.

\section{NOTES}

1. Un intéressant ouvrage collectif d'historiens révèle par ailleurs que la vie culturelle sous Vichy a parfois manifesté de l'indépendance vis-à-vis du pouvoir en place. Le film de Henri-Georges Clouzot, Le Corbeau (1943), dans lequel on a pu voir une critique de la délation sous l'Occupation, en fournit un des plus brillants exemples. Cf. Jean-Pierre Rioux, s. dir., La vie culturelle sous Vichy, Bruxelles, Éditions Complexe, 1990 («Questions au XX siècle ») : 28. 